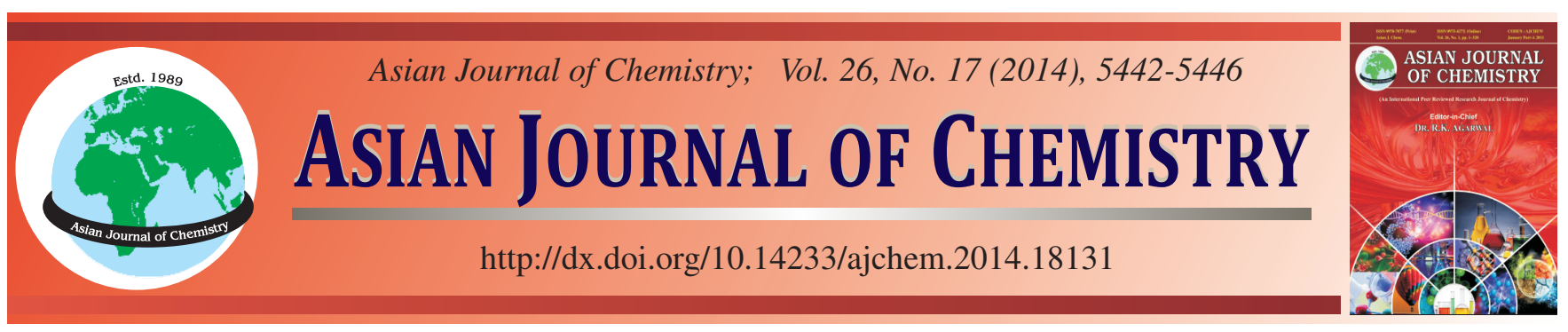

\title{
Study on the Sustained Release and in vitro Efficacy Evaluation of Functionalized Carbon Nanotubes Chitosan Thermo-Sensitive Gel $\dagger$
}

\author{
XiaOjuan $\mathrm{Li}^{1}$, YaKe GuO ${ }^{2}$ and Wen Chen ${ }^{1, *}$ \\ ${ }^{1}$ School of Pharmacy, Medical College, Shihezi University, Shihezi 832000, P.R. China \\ ${ }^{2}$ The First Affiliated Hospital of Medical College of Shihezi University of Xinjiang, Shihezi 832000, P.R. China \\ *Corresponding author: E-mail: chen-wen2000@126.com
}

\begin{abstract}
The purpose of this study was to synthesize a dual release of an amino-carbon nanotubes-chitosan thermo-sensitive gel. The chitosan/ $\beta$ glycerophosphate $(\mathrm{CS} / \beta-\mathrm{GP})$ thermo-sensitive gel loaded with multi-walled carbon nanotubes/polyether imide (MWCNTs-PEI) was prepared by the simple solution casting method. The product was characterized by scanning electron microscopy and a fourier transform infrared spectrometer. Additionally, its toxic effect on PC12 cells was studied and the toxicity levels were evaluated. Nerve growth factor (NGF) was loaded by the CS/ $/$-GP/ MWCNTs-PEI gel. Its release property and biological activity were investigated using PC12 cells in culture media. The SEM and FTIR results showed that, after the MWCNTs-PEI were added, the pore size of the gel significantly decreased and its structure become more compact, which improved its sustained-release ability. The cumulative release of nerve growth factor decreased gradually as the added amount of MWCNTs-PEI increased and the cell differentiation rate reduced accordingly. The MTT experiments demonstrated that the relative growth rate of PC12 cells incubated with the thermo-sensitive gel ranged from 80.4$112 \%$, which reaches the biological material security evaluation criteria. The prepared gels displayed low toxicity as well as good sustained release ability, indicating they can be used as sustained release drug carrier.
\end{abstract}

Keywords: Chitosan/ $\beta$-glycerophosphate thermo-sensitive gel, MWCNTs-PEI, NGF, PC12 cell.

\section{INTRODUCTION}

Since the year 2000, the chitosan thermo-sensitive gel has been a novel injectable gel. Its three-dimensional network structure provides a favourable micro-environment for cell proliferation, migration and differentiation as well as for guiding the ingrowth of host cells. Therefore, it attracts ever-growing attention in tissue regeneration, cell delivery, cell therapy and other fields ${ }^{1}$. Chenite et al. ${ }^{2}$ successfully prepared the first natural polymer chitosan/glycerophosphate gel, which can be used as an injectable gel for local sustained-release drug delivery. However, due to its large aperture and low intensity, a chitosan/ glycerophosphate gel serving as drug delivery carrier typically suffers from burst release ${ }^{3}$, which does not meet the stable release requirements of an implantable drug.

The hyperbranched polymer (HBP) has been popular since the 1980s because of its high solubility, low viscosity, rich terminal functional groups and an internal cavity structure ${ }^{4}$. Therefore, the HBP is advantageous for various biomedical applications; e.g., it increases drug release and solubility and the terminal active groups of HBPs provide a new means for functionalized carbon nanotubes ${ }^{5}$. The hyperbranched polymer polyethylen imine (PEI) is a cationic polymer that is rich in amino groups and due to its good biocompatibility, is widely used in biomedicine. It not only be used as gene carrier to adsorb and concentrate DNA, thus helping them enter into cells, but it can also be used as the base material of neuronal cells in order to promote cell growth. Hu et al. ${ }^{6,7}$ found that a stent made from SWCNTs-PEI can promote the increase of nerve synapses and branching points. Matsumoto et al. ${ }^{8}$ found that MWCNTs covalently coated with nerve growth factor (NGF) can promote the growth and differentiation of chick dorsal root ganglion cells and PC12 cells, similar to the watersoluble nerve growth factor.

This study aims to develop a system based upon the MWCNTs-PEI/CS/ $\beta$-GP thermo-sensitive gel and loaded with NGF, in addition to characterizing and studying its structure and in vitro release of NGF. Using the PC12 cells, the studies investigated the effect of a MWCNTs-PEI/CS/ $\beta$-GP gel on the relative growth rate (RGR) by using the MTT assay as well as evaluated the cell toxicity grade and NGF's biological activity was measured by a PC12 cell culture. 


\section{EXPERIMENTAL}

MWCNTs (OD about 20-40 nm, Length $<5 \mu \mathrm{m}$ ) were purchased from the Nanotech Port Co. Ltd Company, Shenzhen, China. The chitosan was purchased from Sigma with $90 \%$ purity or greater degree of deacetylation. The ellagic acid and disodium $\beta$-GP (glycerol 2-phosphate disodium salt hydrate) were also obtained from Sigma Aldrich. The RPMI 1640, phosphate buffers saline (PBS), horse serum and fetal bovine serum (FBS) were obtained from Gibco, America. The PC12 cells were purchased from the Type Culture Collection of the Chinese Academy of Sciences, Shanghai, China. Other reagents were purchased from local companies and used without further purification.

Synthesis of MWCNTs-PEI: To obtain MWCNTs-PEI, dried MWCNTs-COOH (10 mg) was dispersed into $2 \mathrm{~mL}$ $\mathrm{SOCl}_{2}$ and $100 \mu \mathrm{L} \mathrm{DMF}$, then the solution was kept at $40{ }^{\circ} \mathrm{C}$ for $24 \mathrm{~h}$. The mixture was washed five times with $\mathrm{DMF}$ and then dispersed into $800 \mu \mathrm{L}$ DMF. The last step was the solubilization of PEI $(93.0 \mathrm{mg})$ in $400 \mu \mathrm{L}$ of DMF, adding $200 \mu \mathrm{L}$ triethylamine and then sonicating at $50{ }^{\circ} \mathrm{C}$ for $48 \mathrm{~h}$. The mixtures were dialyzed with water for 3 days and then freeze-dried for $48 \mathrm{~h}$. Finally, the MWCNTs-PEI nanocomposite membranes were ready for testing and characterizations.

Synthesis of MWCNTs-NGF: $0.5,3.0$ and $5.0 \mathrm{mg}$ of MWCNTs-PEI complexes were dissolved into $1.0 \mathrm{~mL}$ of PBS solution and then $100 \mu \mathrm{L} \mathrm{NGF}(20 \mu \mathrm{g} / \mathrm{mL}$ in PBS $)$ was added into the mixture. To obtain a MWCNTs-NGF complex solution, the mixture was magnetically stirred for $24 \mathrm{~h}$ at room temperature.

Synthesis of MWCNTs-NGF/CS/ $\boldsymbol{\beta}-$ GP Thermosensitive gel: A $2 \%(\mathrm{w} / \mathrm{v})$ chitosan solution was prepared by stirring powdered chitosan in hydrochloric acid $(0.1 \mathrm{~mol} / \mathrm{L})$ and then the MWCNTs-NGF complex was added into solution. $400.0 \mathrm{mg}$ of $\beta$-GP was dissolved into $1.0 \mathrm{~mL}$ of distilled water. Then, the $\beta$-GP solution was added dropwise to the chitosan solution under constant stirring and the resulting mixture was stirred for an additional $10 \mathrm{~min}$ under aseptic conditions. The final $\mathrm{pH}$ was adjusted to 7 by a saturated disodium hydrogen phosphate solution. The previous methods were for the MWCNTs-NGF/CS/ $\beta-G P$ sol. The CS/ $\beta-G P / N G F$ sol was prepared by using equal amounts of NGF instead of MWCNTsNGF.

\section{Preparation of thermo-sensitive gel sample solution}

Preparation of thermo-sensitive gel: Chitosan was autoclaved at $121^{\circ} \mathrm{C}$ for $20 \mathrm{~min}$, allowed to cool to room temperature and then $5 \mathrm{~mL}$ hydrochloric acid $(0.1 \mathrm{~mol} / \mathrm{L})$ was added. Next, $1 \mathrm{~mL} 5 \mathrm{mg} / \mathrm{mL}$ of sterilized MWCNTs-PEI complex solution was added. $400 \mathrm{mg}$ of $\beta$-GP was dissolved into $1 \mathrm{~mL}$ of sterilized water, mixed and then filter sterilized. The $\beta-G P$ solution was added dropwise to the mixed chitosan solution and the $\mathrm{pH}$ was adjusted to 7 with a saturated disodium hydrogen phosphate solution. These methods are for the CS/ $\beta$-GP sol loaded with MWCNTs-PEI; however, the CS/ $\beta$-GP sol can be prepared without the MWCNTs-PEI complexes.

Preparation of MWCNTs-PEI/CS/ $\beta$-GP thermosensitive gel extracts: The thermo-sensitive gel was based upon the $0.02 \mathrm{~g} / \mathrm{mL}$ standard. $20 \mathrm{mg}$ of MWCNTs-PEI/CS/ $\beta$ -
GP thermo-sensitive gel materials were added to different volumes of cell culture medium so as to prepare four kinds of thermo-sensitive gel extracts, corresponding to the standard concentrations of 50,10, 2 and 0.2 times. A positive control group was prepared with pure lead materials, which was filter sterilized.

Preparation of MWCNTs-NGF/CS/ $\beta$-GP thermosensitive gel sustained-release liquid: $3 \mathrm{~mL}$ of the MWCNTs$\mathrm{NGF} / \mathrm{CS} / \beta-\mathrm{GP}$ sol were added into a sterile centrifuge tube and the gel formed at $37.0 \pm 0.5^{\circ} \mathrm{C}$. Then, $1.0 \mathrm{~mL}$ PBS was added at the same temperature. This gel was compared to one produced without the addition of MWCNTs-NGF. Furthermore, only the same amount of NGF of CS/ $\beta$-GP thermosensitive gel was added.

Studies on thermo-sensitive gel release performance: The NGF released from the thermo-sensitive gel was quantified over time by an in vitro release assay. $3 \mathrm{~mL}$ of the $\mathrm{CS} / \beta-\mathrm{GP}$ sol loaded with MWCNTs-NGF were added to a sterile centrifuge tube and allowed to completely form into a gel at $37.0 \pm$ $0.5{ }^{\circ} \mathrm{C} .1 \mathrm{~mL}$ aliquots of the release medium were sampled and after the aliquots were taken, the same amount of fresh PBS was added into the containers. The sample's NGF was measured by ELISA kits so as to calculate the NGF cumulative release rates of the CS/ $\beta$-GP thermo-sensitive gel.

\section{in vitro Evaluation of thermo-sensitive hydrogel}

Studies on PC12 cytotoxicity: To investigate the sample's toxic effect on cell culture, PC12 cells were seeded onto each well of 96-well plates at a density of $2.5 \times 10^{4}$ cells/well in $1 \mathrm{~mL}$ of culture media and then were incubated for $24 \mathrm{~h}$. Different MWCNTs-PEI/CS/ $\beta$-GP thermo-sensitive gel extracts were added to each well. We removed a culture plate after it had incubated for 24, 48, 72 and $96 \mathrm{~h}$. At the end of each experiment, $20 \mu \mathrm{L}$ MTT $(1 \mathrm{mg} / \mathrm{mL})$ was added into each well and incubated for $4 \mathrm{~h}$. Then, the medium was discarded and then $150 \mu \mathrm{L}$ dimethyl sulfoxide was added and the plate was incubated again for $10 \mathrm{~min}$. The absorbance was then measured at $490 \mathrm{~nm}$ using an enzyme-linked immunosorbent assay (ELISA) plate reader. According to the following formula-calculated relative growth rates, values were assigned according to the evaluated cytotoxicity levels ${ }^{9,10}$ (Table-1). That is, cytotoxicty is 0 or 1 for eligibility; cytotoxicity is 2 for comprehensive analysis and evaluation, which should be combined with cell morphology and cytotoxicity is 3-5 for failure.

$$
\mathrm{RGR}=\frac{\mathrm{OD}_{\text {experiment }}-\mathrm{OD}_{\text {experiment Blank }}}{\mathrm{OD}_{\text {Control }}-\mathrm{OD}_{\text {Control BLANK }}} \times 100 \%
$$

TABLE-1

\begin{tabular}{cc} 
TABLE-1 \\
RELATIONSHIP BETWEEN THE RELATIVE \\
GROWTH RATE (\%) AND THE CELL'S TOXICITY \\
\hline Relative growth rate (\%) & Toxicity levels \\
\hline$\geq 100$ & 0 \\
$75-99$ & 1 \\
$50-74$ & 2 \\
$25-49$ & 3 \\
$1-24$ & 4 \\
0 & 5 \\
\hline
\end{tabular}


MWCNTs-NGF/CS/ $\beta$-GP thermo-sensitive gel's effect on PC12 cell activity: The fifth generation of PC12 cells was seeded onto 24 well plates at a density of $2.5 \times 10^{4}$ cells/well. After incubating for $24 \mathrm{~h}$, the original cell broth was discarded, release fluid was added and then the plate was cultured for 72 h. Each well was selected three horizons under an inverted microscope randomly; finally, the PC12 cell differentiation rate was calculated. Each experiment was repeated three times.

Statistical analysis: The correlation analysis was conducted by SPSS 13.0; all data are presented as mean \pm standard deviation. Significant differences in the release profile, degradation rate and cell activity were analyzed by a one-way ANOVA test. The differences in groups and experimental time points at any time were considered significant if $p<0.05$.

\section{RESULTS AND DISCUSSION}

Appearance and tactile observation: The CS/ $\beta-$ GP gel is a clear, colourless transparent solution that is highly fluid at room temperature, (Fig. 1A). After MWCNTs-PEI are added into the solution, the gel becomes a uniformly black solution (Fig. 1B). At $37^{\circ} \mathrm{C}$, the chitosan hydrophobic interactions and hydrogens between the chitosan chains were bonding in a dominant position and the chitosan chain was a curved, crosslinked structure. The mobility reduced, viscosity increased and a semi-solid gel was formed. The CS/ $\beta$-GP gel was a milky semi-solid, but it could not flow (Fig. 1C). After loading the MWCNTs-PEI, the gel became a black semi-solid of certain flexibility; however, it could not flow (Fig. 1D).

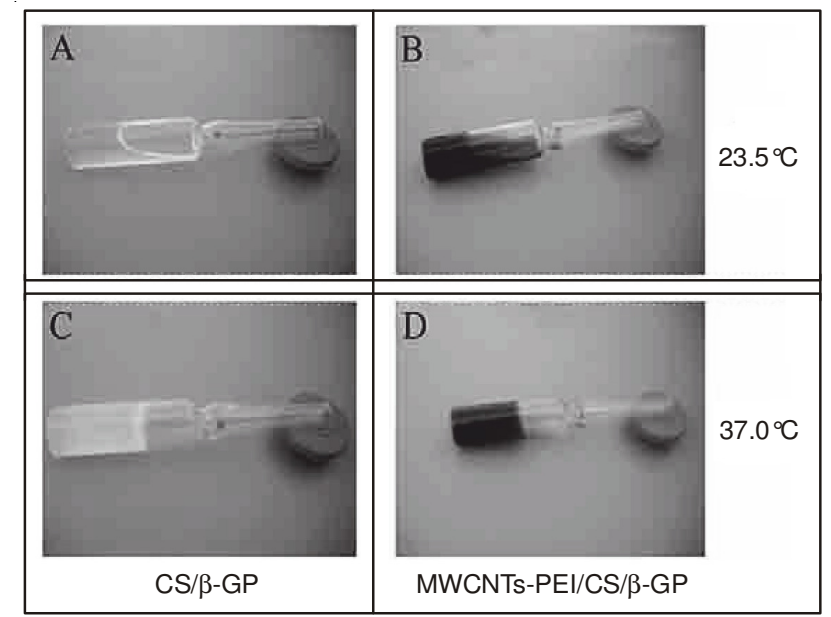

Fig. 1. Sol-gel phase transition graphs of a thermo-sensitive chitosan gel. (A. CS/ $\beta$-GP sol, B. MWCNTs-PEI/CS/ $\beta-$ GP sol, C. CS/ $\beta-$ GP gel and D. MWCNTs-PEI/CS/ $\beta-G P$ gel)

Scanning electron microscopy: Fig. 2 shows an SEM image of the CS/ $\beta$-GP and MWCNTs-PEI/CS/ $\beta-$ GP gel. Dehydration causes voids to form inside the gel because the hydrogenbonds between the gel polymer and the water molecules gradually break during the heating process. Before the addition of MWCNTs-PEI, the CS/ $\beta$-GP gel's lamellar structure is relatively loose and its network structure is apparent. Furthermore, many large through-holes exist in the gel (Fig. 2A). However, the gel pores become significantly smaller in the MWCNTsPEI/CS/B-GP gel (Fig. 2B) and the MWCNTs-PEI are uniformly dispersed in the lamellar structure.
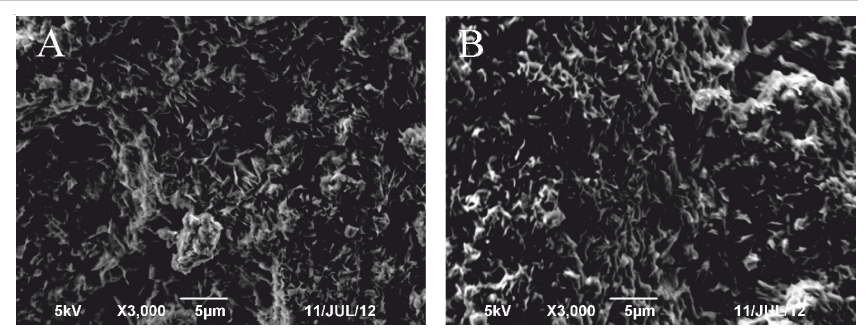

Fig. 2. SEM images of a thermo-sensitive gel. (A. CS/ $\beta$-GP gel and B. MWCNTs-PEI/CS/ $\beta$-GP gel)

FTIR spectra: The FTIR spectra are shown in Fig. 3. Compared to the CS/ $\beta$-GP gel and MWCNTs-PEI/CS/ $\beta$-GP gel (Fig. 3D, 3E), the characteristic peaks of chitosan changed after becoming a gel. On the one hand, the interaction between $-\mathrm{NH}_{2}$ and the added inorganic particles and the formation of coordination bonds lead to a migration of the atomic electron cloud of amino nitrogen, which results in the peaks at 3442 $\mathrm{cm}^{-1}$ that are due to the $-\mathrm{OH}$ and $-\mathrm{NH}_{2}$ stretching vibration shifting to 3363 and $3394 \mathrm{~cm}^{-1}$. On the other hand, the amino bending vibration absorption peak disappears at $1601 \mathrm{~cm}^{-1}$ and a red shift occurs in the hydroxyl bending vibration absorption peak at $1649 \mathrm{~cm}^{-1}$, indicating that the two components formed hydrogen bond complexes. The FTIR spectra of the MWCNTs-PEI/CS/ $\beta$-GP gel contains both the CS/ $\beta$-GP gel and MWCNTs-PEI complex characteristics' absorption peaks, which suggests that the amino compound and the added MWCNTs-PEI complexes formed a coordination bond. It infers that the MWCNTs-PEI complexes' effect on the gel's original network structure results from the formation of hydrogen bonds between them.

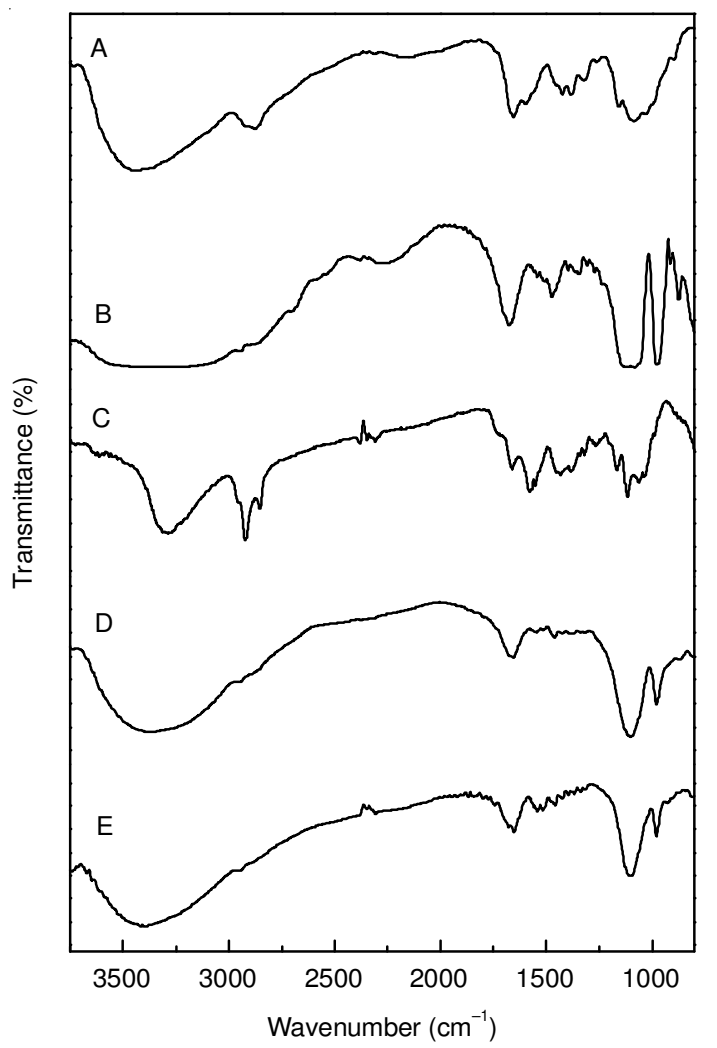

Fig. 3. FTIR spectra of athermo-sensitive gel. (A. CS, B. $\beta$-GP, C. MWCNTs-PEI, D. CS/ $\beta$-GP gel and E. MWCNTs-PEI/CS/ $\beta$-GP gel) 
Release in vitro of thermo-sensitive gel: Fig. 4 exhibits the release of NGF in PBS solution. In 15 days, the cumulative release of NGF in the CS/ $\beta$-GP gel reached $63.29 \%$, while that in the gel loaded with MWCNTs-NGF was less than $60 \%$. As the amount of MWCNTs-PEI increases, the cumulative release rate of NGF decreases, suggesting that the sustaining release of NGF in the MWCNTs-CS/ $\beta$-GP gel is a synergetic function of the MWCNTs-PEI and CS gel. Nerve growth factor primarily spread out through the gel's pores and the gel structure became tighter with greater additions of MWCNTs-PEI, which makes it more slow for the drug molecule to release from the network structure and thus, results in a slow release rate of NGF.

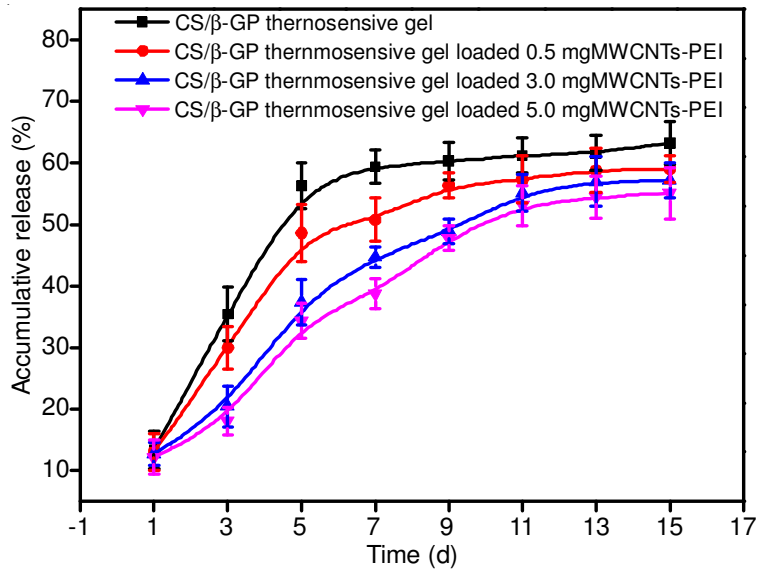

Fig. 4. NGF release curve in vitro of thermo-sensitive gel $(n=3)$

Effect of thermo-sensitive gel on the cytotoxicity of PC12 cells: The effect of the CS/ $\beta-$ GP and MWCNTs-PEI/ $\mathrm{CS} / \beta-\mathrm{GP}$ extract on the growth rate of PC12 cells at different time points was investigated by MTT (Figs. 5 and 6). Compared to the negative control group, positive control group and each concentration group, the cells' relative growth rates for the various concentrations of the CS/ $\beta$-GP gel group were not statistically significant $(p>0.05)$ after culturing for $24 \mathrm{~h}$. The negative control group's survival rate was higher than that of the positive control group $(p<0.05)$ after culturing for $48 \mathrm{~h}$ and the survival rate of each concentrations was higher than that of the positive control group $(p<0.01)$ after culturing for $72 \mathrm{~h}$.

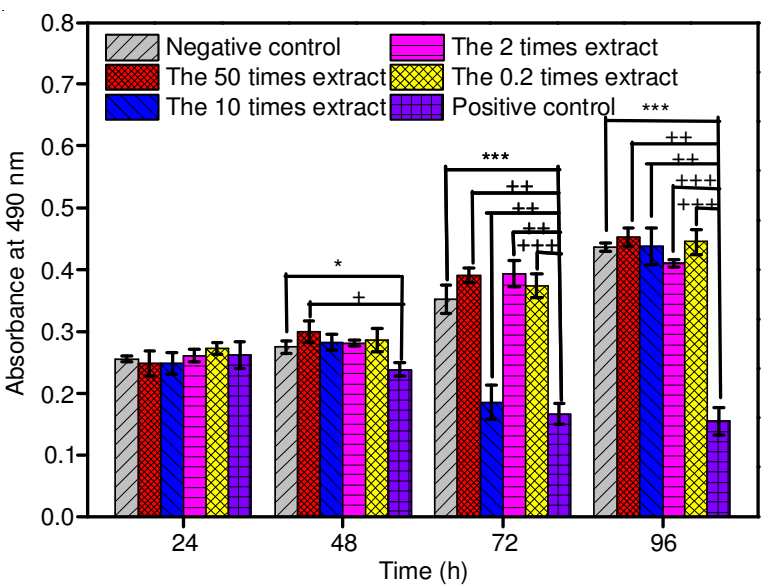

Fig. 5. Effect of different concentrations extract of thermo-sensitive CS/ $\beta$-GP gel on the relative growth rate of PC12 cells at different time points $(n=6)$

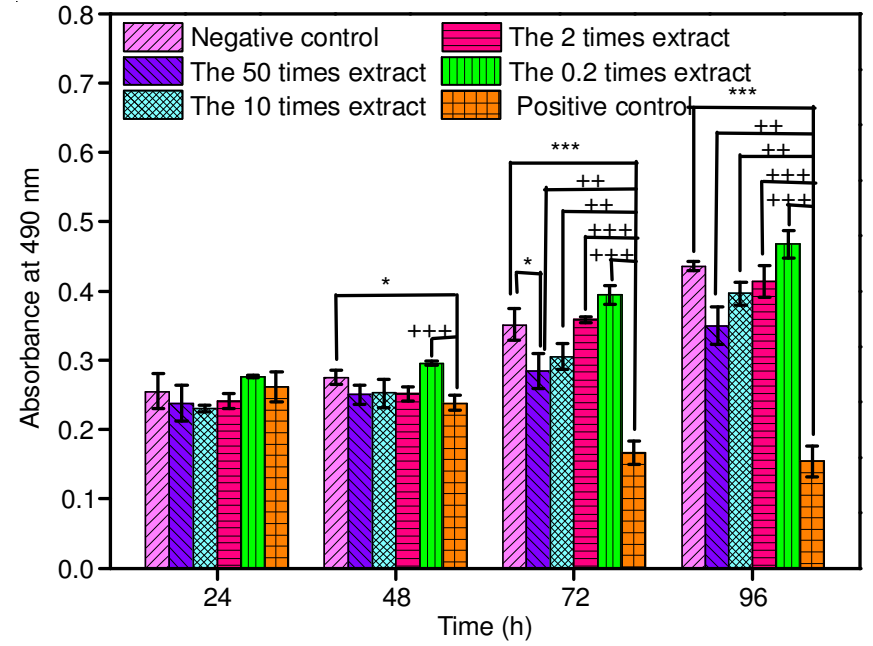

Fig. 6. Effect of different concentrations extract of thermo-sensitive MWCNTs-PEI/CS/ $\beta$-GP gel on the relative growth rate of PC12 cells at different time points $(n=6)$

Table-2 shows the relative growth rates and cell toxicity grades for different time points. The toxic grade of the extract at both high and low concentrations is either 0 or 1 for each time point (24, 48, 72 and $96 \mathrm{~h})$, illustrating that the prepared agent reaches biological material safety evaluation criteria.

States of differentiated PC12 cells: PC12 cells have two states i.e., an undifferentiated and differentiated state. Undifferentiated PC12 cells are tumor cells. They are mostly round and show slow proliferation and poor adherence ability, have no neurons and tend to be small clusters (Fig. 7). After an addition of NGF, the PC12 cells start to differentiate and synapses grow in the cells, suggesting that the PC12 cells have neuronal characteristics. Furthermore, the cells have strong adherence ability, stop dividing, grow protrusions similar to sympathetic neurons and increase in size. The length and amount of the projections increase and form a network. However, they have no proliferation.
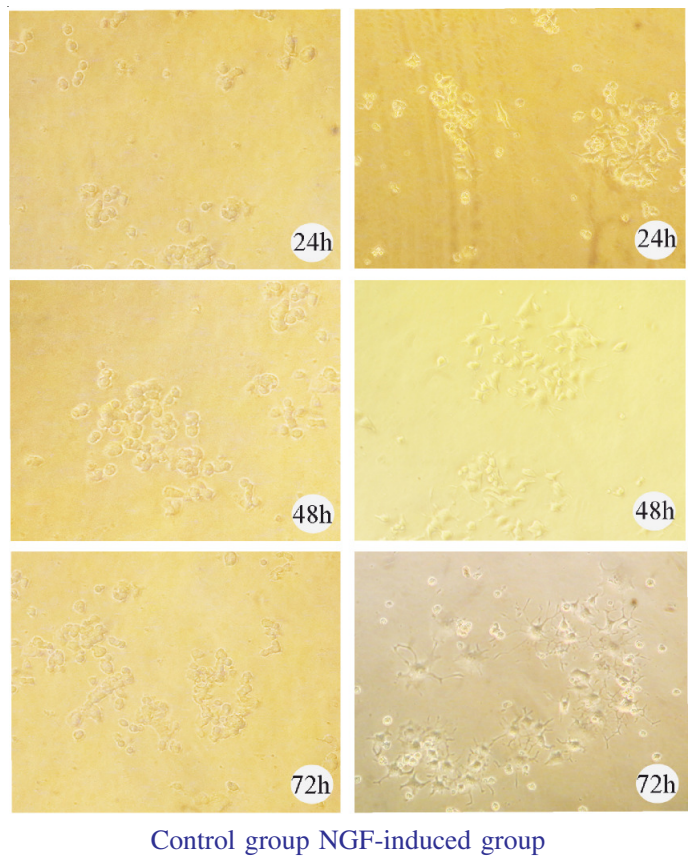

Fig. 7. Effect of NGF on PC12 cell morphology $(\times 200)$ 
TABLE-2

RELATIVE GROWTH RATE (RGR) AND CELL TOXICITY GRADES FOR DIFFERENT TIME POINTS

\begin{tabular}{|c|c|c|c|c|c|c|c|c|c|}
\hline & \multirow{2}{*}{ Group } & \multicolumn{2}{|c|}{$24 \mathrm{~h}$} & \multicolumn{2}{|c|}{$48 \mathrm{~h}$} & \multicolumn{2}{|c|}{$72 \mathrm{~h}$} & \multicolumn{2}{|c|}{$96 \mathrm{~h}$} \\
\hline & & RGR (\%) & Grade & RGR (\%) & Grade & RGR (\%) & Grade & RGR (\%) & Grade \\
\hline \multirow{5}{*}{$\begin{array}{c}\mathrm{CS} / \beta-\mathrm{GP} \\
\text { gel }\end{array}$} & Negative control & 102.6 & 0 & 86.7 & 1 & 47.3 & 3 & 35.4 & 3 \\
\hline & 50 times extract & 97.3 & 1 & 108.9 & 0 & 111.0 & 0 & 103.8 & 0 \\
\hline & 10 times extract & 97.2 & 1 & 103.0 & 0 & 109.6 & 0 & 100.5 & 0 \\
\hline & 2 times extract & 102.1 & 0 & 102.1 & 0 & 111.7 & 0 & 94.0 & 1 \\
\hline & 0.2 times extract & 106.8 & 0 & 104.2 & 0 & 106.2 & 0 & 102.1 & 0 \\
\hline \multirow{4}{*}{$\begin{array}{l}\text { MWCNTs- } \\
\text { PEI/CS/ } \beta- \\
\text { GP gel gel }\end{array}$} & 50 times extract & 93.3 & 1 & 90.9 & 1 & 80.9 & 1 & 80.4 & 1 \\
\hline & 10 times extract & 90.2 & 1 & 91.8 & 1 & 86.8 & 1 & 90.8 & 1 \\
\hline & 2 times extract & 94.5 & 1 & 91.5 & 1 & 101.9 & 0 & 95.0 & 1 \\
\hline & 0.2 times extract & 108.5 & 0 & 107.6 & 0 & 112.0 & 0 & 107.3 & 0 \\
\hline
\end{tabular}

Cell activity of MWCNTs-NGF/CS/ $\beta$-GP thermosensitive gel: Nerve growth factor can inhibit proliferation and induce cell differentiation. The emerged protrusions were used to evaluate the NGF activity ${ }^{11,12}$ (Fig. 8). Compared to the positive control group, the effect of the CS/ $\beta$-GP gel and MWCNTs-NGF/CS/ $\beta-G P$ gel on the PC12 cell activity is significantly different $(p<0.05)$ at $1,3,5,7$ and $9 \mathrm{~d}$. They potentially promote the differentiation of PC12 cells. Subsequently, the NGF activity of the CS/ $\beta$-GP gel group more obviously increased. However, the NGF activity in the CS/ $\beta$ GP gel group and MWCNTs-NGF/CS/ $/$-GP gel group showed no significant difference $(p>0.05)$ at $11 \mathrm{~d}$. The NGF activity in the MWCNTs-NGF/CS/ $\beta$-GP gel group was lower than that in the CS/ $\beta$-GP gel group at the same time point and they showed a significant difference $(p<0.05)$ between 3 and $5 \mathrm{~d}$.

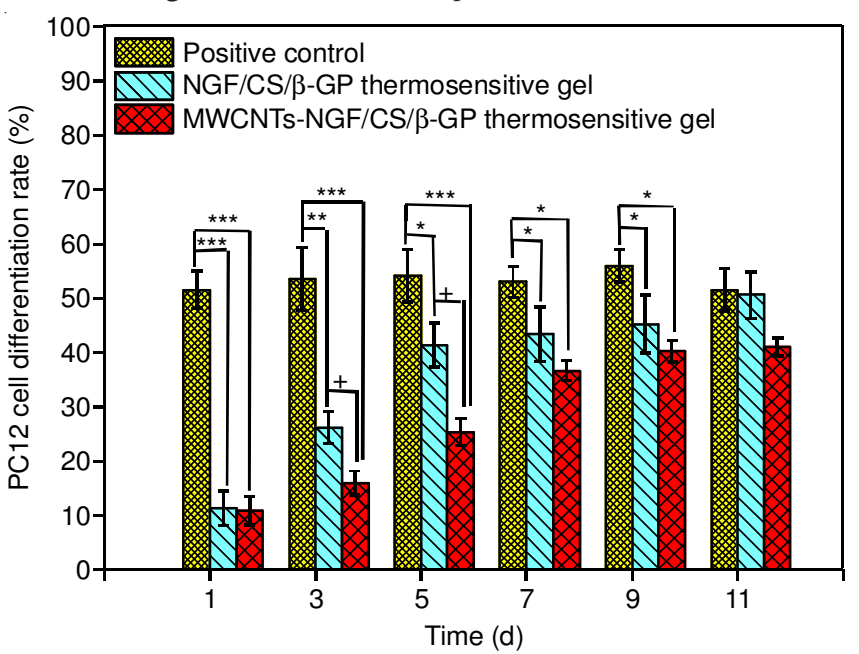

Fig. 8. Differentiation ratio of the PC12 cells $(n=6)$

\section{Conclusion}

Research conducted on the thermo-sensitive gel as a novel sustained-release drug delivery system is still in its preliminary state and there are still some issues that need to be further addressed. The thermo-sensitive gel typically has a large aperture, high water content and low intensity, but one of the most prominent problems is the "burst release" phenomenon when drug-loaded liquid preparations enter into the body to form $\mathrm{gel}^{3}$. This phenomenon is primarily due to the slow gel formation and the remaining liquid preparations accelerate the drug release rate. Another possible cause is related to the gel shape in the administration site. Since the system is a liquid delivery, different gel shapes result in various surface areas being injected into the body, which leads to different drug release rates.

A study found that the CS/GP gel drug delivery system has a poor sustained release for small molecules, whereas drugs of a relative molecular mass of 12,000 to 14,800 can slowly release for up to a few days in this system ${ }^{13}$. This is perhaps because the gel has a large pore network and large water content, an environment in which small molecule drugs can easily diffuse $^{14}$. In this experiment, the study indicates that this support has a low toxicity and slow release ability, which could serve as a very promising new drug delivery system. Therefore, the thermo-sensitive gel system provides a theoretical basis for sustained release. This article only examines the application of the obtained gel as a carrier for water-soluble macromolecular drugs, so we will further study its use as a carrier for small molecule drugs and insoluble drugs.

\section{ACKNOWLEDGEMENTS}

This study was supported by grants from the National Natural Science Foundation of China (No. 81160395). The authors thank Prof. Wen Chen and Dr. Yingchun Li for their support and helpful discussions.

\section{REFERENCES}

1. N. Bhattarai, J. Gunn and M. Zhang, Adv. Drug Deliv. Rev., 62, 83 (2010).

2. A. Chenite, C. Chaput, D. Wang, C. Combes, M.D. Buschmann, C.D. Hoemann, J.C. Leroux, B.L. Atkinson, F. Binette and A. Selmani, Biomaterials, 21, 2155 (2000).

3. G.D. Kang, S.H. Cheon, G. Khang and S.-C. Song, Eur. J. Pharm. Biopharm., 63, 340 (2006).

4. W. Tian, X. Fan, J. Kong, Y. Liu, T. Liu and Y. Huang, Polymer, 51, 2556 (2010).

5. Y.L. Zeng, Y.F. Huang, J.H. Jiang, X.-B. Zhang, C.-R. Tang, G.-L. Shen and R.-Q. Yu, Electrochem. Commun., 9, 185 (2007).

6. H. Hu, Y. Ni, S.K. Mandal, V. Montana, B. Zhao, R.C. Haddon and V. Parpura, J. Phys. Chem. B, 109, 4285 (2005).

7. H. Hu, Y. Ni, V. Montana, R.C. Haddon and V. Parpura, Nano Lett., 4, 507 (2004).

8. K. Matsumoto, C. Sato, Y. Naka, R. Whitby and N. Shimizu, Nanotechnology, 21, 115101 (2010).

9. C. Richard, F. Balavoine, P. Schultz, T.W. Ebbesen and C. Mioskowski, Science, 300, 775 (2003).

10. S. Yip, Nat. Mater., 2, 3 (2003).

11. K. Huff, D. End and G. Guroff, J. Cell Biol., 88, 189 (1981).

12. A. Obermeier, R.A. Bradshaw, K. Seedorf, A. Choidas, J. Schlessinger and A. Ullrich, EMBO J., 13, 7 (1994).

13. E. Ruel-Gariépy, M. Shive, A. Bichara, M. Berrada, D. Le Garrec, A. Chenite and J.-C. Leroux, Eur. J. Pharm. Biopharm., 57, 53 (2004).

14. E. Ruel-Gariepy, G. Leclair, P. Hildgen, A. Gupta and J.-C. Leroux, J. Control. Rel., 82, 373 (2002). 